\title{
Non-prescriptionxx antibiotic use for people aged 15 years or older for cough in China: a community-based survey
}

\author{
Yan Luo ${ }^{1,2 \dagger}$, Xuewen Tang ${ }^{1 \dagger}$, Linling Ding ${ }^{1}$, Zhujun Shao ${ }^{3}$, Jianxing Yu ${ }^{3}$, Yangqing Chen ${ }^{4}$, Yang Zhou ${ }^{1}$,
} Hanqing $\mathrm{He}^{1 *}$ (D) and Zhiping Chen ${ }^{1 *}$

\begin{abstract}
Background: Non-prescription antibiotic use at community is a main driver of antimicrobial resistance. Cough is a common condition and prevalent in all townships, including China. This study aims to investigate the non-prescription antibiotic use for cough in China and explore to which extent antibiotic use knowledge was correctly instructed in communities.

Methods: A probability-proportionate-to-size sampling method was adopted to survey from all 14 townships in Yiwu city, China. All participants were investigated by face-to-face interview on Portable Android Devices. The continuous variables were presented by mean and standard deviation or medium and inter-quartile range (IQR). The categorical variables were presented using percentage or constituent ratio. Chi-square test for univariate analysis and logistic regression for multivariate analysis were conducted to assess the odds ratios and 95\% confidence intervals, respectively.
\end{abstract}

Results: A total of 3034 respondents across all the 14 townships and the 50 natural villages/streets completed all key items of the questionnaire. Of 2400 (79.10\%) respondents stated that they experienced cough in the past 12 months with the medium age of 36.5 (IQR: $26-49)$ and 12.21\% (293/2400) respondents had the non-prescription antibiotic use behavior. Among those 293 respondents, the proportion of non-prescription antibiotic use for cough peaked at around 16\% among people aged 30-39 years old. The major sources of antibiotics were pharmacy (77.70\%) and/or family storage (43.92\%).

Conclusions: Non-prescription antibiotics use for cough is prevalent in the community, especially among people in their thirties. Strengthened drug purchase regulation and well-trained professional pharmacists would be promising alternatives to ameliorate AMR. Moreover, penetrating antibiotics knowledge to common citizens and is an urgent task to alleviate antimicrobial resistance. Therefore, proactive policies and regulations should be made to improve current situations.

Keywords: Non-prescription, Antibiotic use, Cough, Community-based

*Correspondence: hanqinghe@cdc.zj.cn; zhpchen@cdc.zj.cn

${ }^{\dagger}$ Yan Luo and Xuewen Tang have contributed equally to this work 1 Institute for Immunization and Prevention, Zhejiang Provincial Center for Disease Control and Prevention, No. 3399 Binsheng Road, Binjiang district, Hangzhou City 310051, Zhejiang Province, China

Full list of author information is available at the end of the article

\section{Introduction}

China is a country with a high consumption of antibiotics. According to the published data, each Chinese consumes $138 \mathrm{~g}$ of antibiotics per year. The quantity is 9 times higher than the United States [1]. Among the various accessibility to antibiotics, non-prescription use of original author(s) and the source, provide a link to the Creative Commons licence, and indicate if changes were made. The images or other third party material in this article are included in the article's Creative Commons licence, unless indicated otherwise in a credit line to the material. If material is not included in the article's Creative Commons licence and your intended use is not permitted by statutory regulation or exceeds the permitted use, you will need to obtain permission directly from the copyright holder. To view a copy of this licence, visit http://creativecommons.org/licenses/by/4.0/. The Creative Commons Public Domain Dedication waiver (http://creativeco mmons.org/publicdomain/zero/1.0/) applies to the data made available in this article, unless otherwise stated in a credit line to the data. 
antibiotics is prevalent in the community of China [2]. Non-prescription use of antibiotics increases the risk of inappropriate use, which is accelerating the process of antimicrobial resistance (AMR) and is the main driver in the development of drug-resistant pathogens [3]. AMR is more challenging in developing countries because the health system is more vulnerable $[4,5]$. China, as the largest developing country, with one fifth of the world's population, therefore, non-prescription dispensing of antibiotics at community indeed is a global issue. China also has the most rapid growth rate of AMR globally [6]. In the past decade, China launched some health reforms and policies for using antibiotics rationally [7], however, few impacts from those actions were observed $[8,9]$.

Cough and expectoration are also prevalent in China $[10,11]$. For Chinese people aged 40 years or older of a national survey in 162 surveillance points, the prevalence rates were $15 \%$ for men and $8 \%$ for women, respectively. Past surveys showed that self-medication with antibiotics is common for people to treat self-limiting illnesses, like coughing, expectoration and upper respiratory tract infection (URTI) [12-14] in China. For example, a survey conducted by the National Medical Products Administration (NMPA) showed that 1892 of 7915 respondents (23.9\%) chose to self-medication antibiotics instead of going to see a doctor when they had symptoms of a cold [12]. Previous studies $[15,16]$ have also shown the nonprescription antibiotic rates at community pharmacies for adult acute URTI without population-based data. In addition, the previous population-based surveys only limited to university students $[14,17]$ or children [18]. These studies have highlighted the seriousness of the non-prescribed and injudicious use of antibiotics, as well as high rate of antibiotic use for cough. However, there is no age-specific community-based accurate data to clarify the non-prescription frequency from a comprehensive view.

We hereby conduct a community-based survey among people aged 15 years and above to study (1) the proportion of non-prescription antibiotic use in population with respiratory disease related symptoms; (2) the sources and types of antibiotics used without prescription among people with respiratory disease related symptoms; (3) explore knowledge related to antibiotics use; and (4) factors that influenced people's behavior of non-prescription antibiotics usage.

\section{Methods}

\section{Study population}

This study was carried out in Yiwu city, Zhejiang Province (approximately 1,318,600 inhabitants) from June to December in 2019. People who aged 15 years or older and had been living in Yiwu for more than 6 months were considered as source population. We selected people for the survey from all 14 townships in Yiwu.

\section{Definition}

Cough: cough (defined as at least 3 days per week and at least 4 times per day) with or without expectoration in the past year (12 months) because of common cold or other reasons $[10,19]$.

Non-prescription antibiotic use: self-medication antibiotics without doctor's prescription and get antibiotic from an unregulated supply chain.

\section{Questionnaire}

The questionnaire used in the survey comprising $3 \mathrm{sec}-$ tions: (1) sociodemographic information; (2) non-prescription antibiotic behaviors during cough; and (3) antibiotic knowledge. People were asked to state the sources and reasons of antibiotic use when they cough and generic names of antibiotics they have used. The 9 knowledge questions related to non-prescription use and overuse of antibiotics.

\section{Data collection}

Investigation was conducted by staffs in centers for disease control and prevention (CDC) by face-to-face communication. All investigators underwent two-round training before investigation. Probability-Proportionateto-Size (PPS) sampling method was adopted to select people for the survey from all 14 townships in Yiwu city, then followed by a simple random sampling. The whole process of randomization and sampling is shown as a flow diagram in Additional file 1: Figure 1. The sample size is calculated by $N=\left(\frac{U_{\alpha / 2}}{\delta}\right)^{2} \pi(1-\pi) \times$ deff $[20$, $21]$. We conservatively assumed that the prevalence of non-prescription use of antibiotics following cough $(\pi)$ as $40 \%$ since there is no previous study for reference; a permissible error $(\delta)$ as $2.5 \%$; a level of significance $(\alpha)$ as $5 \%$ and a design effect (deff) as 2 . With all parameters put in, $\mathrm{n}$ equals to 2950 . Thus, the sample size is around 3000. As for the number of clusters should be no less than $30[21,22]$, we assumed 50 clusters. A sample of 3000 divided into 50 clusters, so there were 60 individuals in each cluster. We chose 50 clusters from all these 14 townships. In each township, the number of cluster $(n)$ was calculated by the following process: (1) we divided the population aged 15 or older in the Yiwu City $(N)$ by 50; (2) the number of clusters $(n)$ equals to the numbers containing the integer multiple of $N / 50$ in the accumulative population interval of its corresponding township. Details on clusters in each township is shown in Additional file 1: Table 1 . Then, we randomly chose $n$ natural villages/streets as $n$ clusters in corresponding township. 
Finally, in each cluster/natural village/street, we stratified by age group $(15-19,20-24,25-29,30-34,35-39$, $40-44,45-49,50-64$ and $\geq 65$ years old) and gender; 60 individuals were investigated according to the age distribution and the gender distribution. We knocked on doors according to the house number to do household investigation and chose only one person in each household. Investigation in each age group completed when its corresponding quota achieved. No-response surveys did not include in the final analysis while reasons of no response were recorded. Data collection was implemented through offline face-to-face interview system on Portable Android Device (PAD). Source data verification and data export was conducted by two investigators for quality control weekly. The data was collected between October 2019 and December 2019.

\section{Statistical analysis}

Data analyses were done using Microsoft Excel 2010 and $\mathrm{R}$ v3.5.1, and $P<0.05$ was considered statistically significant. The continuous variables were presented by mean and standard deviation (SD) or medium and inter-quartile range (IQR). The categorical variables were presented using percentage or constituent ratio. For risk factors that associated with non-prescription antibiotic behavior during cough, we used chi-square test for univariate analysis and logistic regression for multivariate analysis to assess the odds ratios (ORs) and 95\% confidence intervals (CIs), respectively. Cochran-Armitage trend test was used to test the trend of age-specific frequency. Variables with statistically significant or professional significant in univariate analysis were included in the multivariate analysis. The score of antibiotic-related knowledge was calculated by simply adding the number of correct answers and each correct answer equals to one score. A score of $0-3$ was considered as a low level of knowledge, 4-6 was medium and 7-9 was high.

\section{Results}

\section{Sociodemographic characteristics}

A total of 3051 respondents across all the 14 townships and the 50 natural villages/streets participated in the interviews. A total of 3034 (99.44\%) respondents completed all key items of the questionnaire (Table 1). The spectrum of age for recruited participants spanned from 15 to 94 with the medium age of 37 (IQR: 26-49). Specially, 1819 (59.95\%) lived in the urban areas and 1499 (49.41\%) were male. Among the 3034 subjects, 2400 (79.10\%) stated that they experienced cough in the past 12 months; the medium age was 36.5 (IQR: 26-49) (Table 1).
Table 1 The sociodemographic characteristics of study participants

\begin{tabular}{|c|c|c|}
\hline \multirow[t]{2}{*}{ Characteristics } & \multirow{2}{*}{$\begin{array}{l}\text { Total }(n=3034) \\
n(\%)\end{array}$} & \multirow{2}{*}{$\begin{array}{l}\text { Participants with } \\
\text { cough }(n=2400) \\
n(\%)\end{array}$} \\
\hline & & \\
\hline \multicolumn{3}{|l|}{ Age (years) } \\
\hline $15-19$ & $210(6.92)$ & $179(7.46)$ \\
\hline $20-24$ & $420(13.84)$ & $327(13.63)$ \\
\hline $25-29$ & $416(13.71)$ & $329(13.71)$ \\
\hline $30-34$ & $318(10.48)$ & $251(10.46)$ \\
\hline $35-39$ & $312(10.28)$ & $239(9.96)$ \\
\hline $40-44$ & $314(10.35)$ & $250(10.42)$ \\
\hline $45-49$ & $313(10.32)$ & $241(10.04)$ \\
\hline $50-64$ & $417(13.74)$ & $333(13.88)$ \\
\hline$\geq 65$ & $314(10.35)$ & $251(10.46)$ \\
\hline Median (IQR) & $37(26,49)$ & $36.5(26,49)$ \\
\hline \multicolumn{3}{|l|}{ Residence } \\
\hline Urban & $1819(59.95)$ & $1391(57.96)$ \\
\hline Rural & $1215(40.05)$ & $1009(42.04)$ \\
\hline \multicolumn{3}{|l|}{ Gender } \\
\hline Male & $1499(49.41)$ & $1174(48.92)$ \\
\hline Female & $1535(50.59)$ & $1226(51.08)$ \\
\hline \multicolumn{3}{|l|}{ Occupation } \\
\hline Student & $164(5.41)$ & $146(6.08)$ \\
\hline Unemployed & $695(22.91)$ & $582(24.25)$ \\
\hline Business/service/food personnel & $1111(36.62)$ & $831(34.63)$ \\
\hline Professional & $705(23.24)$ & $560(23.33)$ \\
\hline Farmers and workers & $359(11.83)$ & $281(11.71)$ \\
\hline \multicolumn{3}{|l|}{ Education } \\
\hline Primary school and below & $625(20.60)$ & $492(20.50)$ \\
\hline Middle school & $1695(55.87)$ & $1330(55.42)$ \\
\hline College and above & $714(23.53)$ & $578(24.08)$ \\
\hline \multicolumn{3}{|l|}{ Child under 5 years old } \\
\hline No & $1912(63.02)$ & $1528(63.67)$ \\
\hline Yes & $1122(36.98)$ & $872(36.33)$ \\
\hline \multicolumn{3}{|l|}{ Annual household income (CNY) } \\
\hline$<100,000$ & $1789(58.97)$ & $1382(57.58)$ \\
\hline 100,000-199,999 & $902(29.73)$ & $733(30.54)$ \\
\hline$\geq 200,000$ & $343(11.31)$ & $285(11.88)$ \\
\hline \multicolumn{3}{|l|}{ Smoking status } \\
\hline No & $1696(55.9)$ & $1341(55.88)$ \\
\hline Yes & $1338(44.10)$ & $1059(44.13)$ \\
\hline \multicolumn{3}{|l|}{ Chronic disease } \\
\hline No & $2430(80.09)$ & $1891(78.79)$ \\
\hline Yes & $604(19.91)$ & $509(21.21)$ \\
\hline
\end{tabular}

IQR inter-quartile range, CNY Chinese Yuan

\section{Proportions and ratios of non-prescription antibiotics}

Among 2400 participants who experienced cough in the past 12 months, 293 (12.21\%) individuals had the non-prescription behavior. After stratified by age (Fig. 1), non-prescription proportion was ranged from $15.08 \%$ (standard error, $\mathrm{SE}: \pm 2.68$ ) in individuals aged 
15-19 years, 9.48\% (SE: \pm 1.62 ) in people aged $20-24$, to $13.98 \%$ (SE: \pm 1.91 ) in individuals aged $25-29$ years. Then, the proportion was peaked at $16.73 \%$ (SE: \pm 2.36 ) among people in 30-34 years. After slightly dropped to $16.32 \%$ (SE: \pm 2.39 ) in $35-39$ years old, the proportion dramatically decreased to $10.40 \%$ (SE: \pm 1.93 ) in $40-44$ years old. Despite a few fluctuations, the overall proportion was

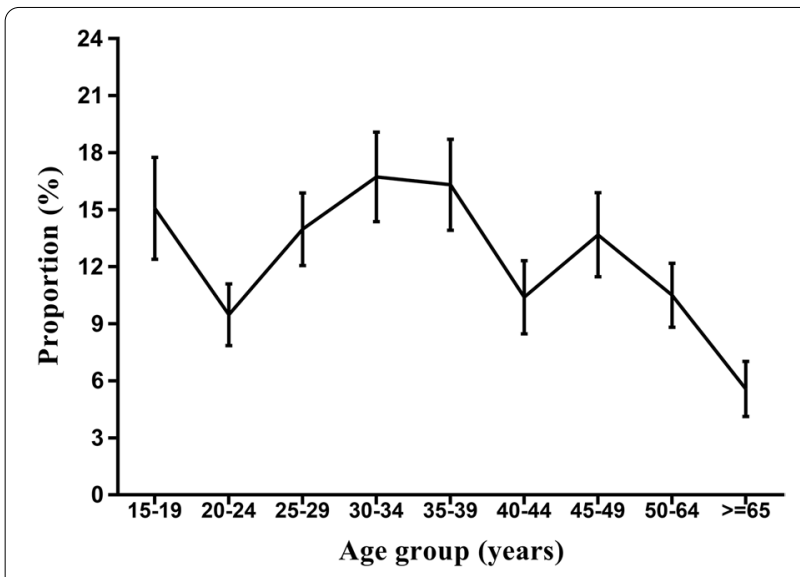

Fig. 1 Age-specific proportions of non-prescription antibiotics use in participants for cough around $10 \%$ (SE: \pm 1.68 ) from 45 to 64 years old, then reached the lowest $5.58 \%(\mathrm{SE}: \pm 1.45)$ in people aged 65 years old or older $\left(Z_{\text {trend }}=-1.358, P_{\text {trend }}=0.1743\right)$ (Fig. 1).

In 293 participants who used antibiotic without prescription when they coughed in the past year are shown in Table 2. The major sources were from pharmacy (77.70\%) and family storage (43.92\%), followed by last remaining antibiotic (13.18\%). Only $5(1.69 \%)$ and 3 (1.01\%) individuals stated that they obtained antibiotic without prescription from friend/colleagues or online, respectively. Then we further undermine the underlying cause for non-prescription antibiotics use, 201 (67.91\%) individuals considered cough was unnecessary to visit a doctor. More than half $(57.09 \%)$ individuals used non-prescription antibiotic as they had antibiotic stored at home. 125 (42.23\%) participants had non-prescribed use because purchasing antibiotics in pharmacy was convenient, and 102 (34.46\%) participants believed that self-treating by antibiotics was effective for cough. The remaining 34 (11.60\%) participants used antibiotic without prescription as they considered going to hospital was time-consuming. Only $1(0.34 \%)$ individual nonprescribed antibiotic use because its safety (Table 2).

Table 2 Details of non-prescription antibiotic use in participants for cough $(N=293)$

\begin{tabular}{|c|c|c|c|}
\hline Antibiotic use & $\mathbf{N}$ & Ratio (\%) & $\begin{array}{l}\text { Ratio of } \\
\text { options } \\
(\%)\end{array}$ \\
\hline \multicolumn{4}{|l|}{ Source } \\
\hline Pharmacy & 230 & 77.70 & 55.83 \\
\hline Family storage & 130 & 43.92 & 31.55 \\
\hline Last remaining antibiotic & 39 & 13.18 & 9.47 \\
\hline Friends or colleagues & 5 & 1.69 & 1.21 \\
\hline Online purchase & 3 & 1.01 & 0.73 \\
\hline \multicolumn{4}{|l|}{ Reasons for non-prescription } \\
\hline Cough is ailment and not necessary to see a doctor & 201 & 67.91 & 31.36 \\
\hline With antibiotic at home & 169 & 57.09 & 26.37 \\
\hline Pharmacy purchase is convenient & 125 & 42.23 & 19.50 \\
\hline Believe self-treating by antibiotic is effective for cough & 102 & 34.46 & 15.91 \\
\hline Too busy to see a doctor & 15 & 5.07 & 2.34 \\
\hline The process of seeing a doctor is too long & 10 & 3.38 & 1.56 \\
\hline Self-treatment by antibiotic is more convenient than go to hospital & 9 & 3.04 & 1.40 \\
\hline Antibiotic is safe & 1 & 0.34 & 0.16 \\
\hline \multicolumn{4}{|l|}{ Antibiotic type } \\
\hline Penicillin & 145 & 48.99 & 38.98 \\
\hline Cephalosporin & 116 & 39.19 & 31.18 \\
\hline Don't remember & 61 & 20.61 & 16.40 \\
\hline Macrolides & 15 & 5.07 & 4.03 \\
\hline Quinolones & 6 & 2.03 & 1.61 \\
\hline
\end{tabular}


Univariable and multivariable analyses for risk factors for non-prescription antibiotic use

Table 3 shows univariate and multivariate analyses results. In multivariable analysis, families with child under 5 years old were less likely to non-prescription use of antibiotic during cough, with an OR of 0.730 (95\% CI
0.552-0.965). Similarly, individuals with chronic diseases were less likely to use antibiotic without prescription when they coughed, with an OR of 0.654 (95\% CI $0.441-$ 0.969). Participants with medium knowledge of antibiotic were more likely to use antibiotic without prescription when compared to those of low knowledge, with an

Table 3 Univariate and multivariate analyses of factors associated with non-prescription antibiotic use in participants for cough $(\mathrm{N}=2400)$

\begin{tabular}{|c|c|c|c|c|c|c|}
\hline \multirow[t]{2}{*}{ Characteristics } & \multicolumn{2}{|c|}{$\begin{array}{l}\text { Non-prescription antibiotic } \\
\text { use }\end{array}$} & \multicolumn{2}{|l|}{ Univariable } & \multicolumn{2}{|l|}{ Multivariable } \\
\hline & $\begin{array}{l}\text { Yes } \\
\mathrm{N}(\%)\end{array}$ & $\begin{array}{l}\text { No } \\
\mathrm{N}(\%)\end{array}$ & Crude OR $(95 \% \mathrm{CI})$ & $P$ value & Adjusted OR (95\% Cl) & $P$ value \\
\hline \multicolumn{7}{|l|}{ Age (years) } \\
\hline $15-29$ & $104(12.46)$ & 731 (87.54) & Reference & 0.003 & Reference & 0.198 \\
\hline $30-44$ & $107(14.46)$ & $633(85.54)$ & $1.170(0.891-1.536)$ & 0.258 & $1.241(0.921-1.671)$ & 0.156 \\
\hline$\geq 45$ & $82(9.94)$ & $743(90.06)$ & $0.644(0.450-0.920)$ & 0.016 & $0.926(0.575-1.491)$ & 0.752 \\
\hline \multicolumn{7}{|l|}{ Residence } \\
\hline Urban & $185(13.30)$ & $1206(86.70)$ & Reference & & Reference & \\
\hline Rural & $108(10.70)$ & $901(89.30)$ & $0.781(0.607-1.006)$ & 0.056 & $0.799(0.617-1.033)$ & 0.087 \\
\hline \multicolumn{7}{|l|}{ Gender } \\
\hline Male & $144(12.27)$ & $1030(87.73)$ & Reference & & Reference & \\
\hline Female & $149(12.15)$ & $1077(87.85)$ & $0.990(0.775-1.264)$ & 0.933 & $1.040(0.805-1.345)$ & 0.762 \\
\hline \multicolumn{7}{|l|}{ Occupation } \\
\hline Student & $18(12.33)$ & $128(87.67)$ & Reference & 0.009 & Reference & 0.185 \\
\hline Unemployed & $60(10.31)$ & $522(89.69)$ & $0.817(0.466-1.432)$ & 0.481 & $1.077(0.561-2.069)$ & 0.823 \\
\hline Business/service/food personnel & $129(15.52)$ & $702(84.48)$ & $1.307(0.771-2.215)$ & 0.321 & $1.244(0.697-2.223)$ & 0.460 \\
\hline Professional & $57(10.18)$ & $503(89.82)$ & $0.806(0.458-1.417)$ & 0.453 & $0.797(0.427-1.486)$ & 0.475 \\
\hline Farmers and workers & $29(10.32)$ & $252(89.68)$ & $0.818(0.438-1.529)$ & 0.530 & $1.045(0.518-2.105)$ & 0.903 \\
\hline \multicolumn{7}{|l|}{ Education } \\
\hline Primary school and below & $39(7.93)$ & $453(92.07)$ & Reference & 0.003 & Reference & 0.074 \\
\hline Middle school & $184(13.83)$ & $1146(86.17)$ & $1.865(1.298-2.679)$ & 0.001 & $1.614(1.069-2.436)$ & 0.023 \\
\hline College and above & $70(12.11)$ & $508(87.89)$ & $1.601(1.060-2.416)$ & 0.025 & $1.602(0.955-2.687)$ & 0.074 \\
\hline \multicolumn{7}{|l|}{ Child under 5 years old } \\
\hline No & $196(12.83)$ & $1332(87.17)$ & Reference & & Reference & \\
\hline Yes & $97(11.12)$ & 775 (88.88) & $0.851(0.657-1.102)$ & 0.221 & $0.730(0.552-0.965)$ & 0.027 \\
\hline \multicolumn{7}{|l|}{ Household income (CNY) } \\
\hline$<100,000$ & $167(12.08)$ & $1215(87.92)$ & Reference & 0.825 & Reference & 0.628 \\
\hline $100,000-199,999$ & $88(12.01)$ & 645 (87.99) & $0.993(0.754-1.307)$ & 0.958 & $0.877(0.654-1.176)$ & 0.382 \\
\hline$\geq 200,000$ & $38(13.33)$ & 247 (86.67) & $1.119(0.767-1.633)$ & 0.559 & $1.020(0.676-1.539)$ & 0.926 \\
\hline \multicolumn{7}{|l|}{ Smoking status } \\
\hline Yes & $134(12.65)$ & 925 (87.35) & Reference & & Reference & \\
\hline No & $159(11.86)$ & $1182(88.14)$ & $0.929(0.726-1.187)$ & 0.554 & $0.977(0.759-1.257)$ & 0.855 \\
\hline \multicolumn{7}{|l|}{ Chronic disease } \\
\hline No & $254(13.43)$ & $1637(86.57)$ & Reference & & Reference & \\
\hline Yes & $39(7.66)$ & $470(92.34)$ & $0.535(0.376-0.761)$ & $<0.001$ & $0.654(0.441-0.969)$ & 0.034 \\
\hline \multicolumn{7}{|l|}{ Knowledge score } \\
\hline $0-3$ & $87(9.68)$ & $812(90.32)$ & Reference & 0.001 & Reference & 0.008 \\
\hline $4-6$ & $134(15.60)$ & $725(84.40)$ & 1.725 (1.294-2.300) & $<0.001$ & $1.511(1.122-2.034)$ & 0.007 \\
\hline $7-9$ & $72(11.21)$ & $570(88.79)$ & $1.179(0.847-1.640)$ & 0.328 & $1.037(0.724-1.485)$ & 0.842 \\
\hline
\end{tabular}

OR odds ratio, $C l$ confidence interval, $C N Y$ Chinese Yuan 
OR of 1.511 (95\% CI: 1.122-2.034). The questions and answers to antibiotic use knowledge of 3034 respondents was shown in Additional file 1: Table 2 (Table 3).

\section{Discussion}

This is the largest and the first community-based study that investigated the nonprescribed antibiotics for cough in China to date. Our findings illustrate the age-specific proportion of non-prescription antibiotic use at community for cough among residents aged 15 years or older because cough is prevalent in China [23]. We found that non-prescription antibiotic use for cough was prevalent despite of factors such as age groups, residence, gender and occupations etc.

The overall proportion of non-prescription is $12.21 \%$ (293/2400) for the source population, which can extrapolate to make a more accurate estimation of the nonprescription antibiotics use population for cough in national-wide. Previous studies showed the proportion was $36 \%$ in China [13] and $48.8 \%$ in a cross-sectional survey among Chinese university students [17], respectively. The inconformity between our study and past studies is due to different sampling strategy. They used the number of people who used antibiotics as denominator, while our study used the people cough in the past year as denominator. By adopting the same calculation as previous studies, the prevalence would therefore be similar to the two aforementioned studies [13,17]. The prevalence is much higher than European countries, for instance, Sweden, Denmark, Netherlands, Austria, Belgium, Ireland and UK, for which the prevalence was approximately $3 \%[13$, 24]. Great importance should be attached to participants in 30-39 years old, they were in the highest prevalence to used antibiotic without prescription. Some surveys reported that middle-east people aged 18-39 years with the highest prevalence while others reported a higher prevalence in people aged $40-59$ years $[25,26]$.

Our study not only informs the high prevalence of nonprescription antibiotics used for cough, but also articulates sources, reasons, and patterns for self-medication. First, the main source of antibiotics is pharmacy, which highlights the easy access to antibiotics in communities. Chinese government launched some reforms for the purpose of using antibiotics reasonably and safely with prescription, while there were small effects on using antibiotics in health facilities. More measures for controlling antibiotics misuse should be taken. Strengthened drug purchase regulation and well-trained professional pharmacists would be promising alternatives to ameliorate AMR in developing countries [5]. Therefore, interventions for reducing non-prescription antibiotics sales in the large number of community pharmacies in China is in urgent need. Strategies involving national guidance on antibiotics for training more qualified pharmacists and delivering the WHO AWaRe antibiotic list [27] in retail shops would be effective ways to enhance pharmacists' knowledge [28]. Second, penicillin and cephalosporin were two most common non-prescription types of antibiotics. Monitoring pharmacies using mobile technologies and/or internet to improve the regulations will be good ways for surveillance [29]. Third, participants' knowledge on antibiotics was relatively low. Delivering pamphlets about antibiotic knowledge for community residence and use antibiotic under qualified pharmacists' construction can be used to enhance people's knowledge and awareness. Fourth, the residual amount of antibiotics that doctors have previously prescribed is also an important factor in misuse. Thus, establishing strict graded management system can promote rational use by limiting antibiotic prescriptions and reducing the amount of antibiotics prescribed.

Under the situation of Corona Virus Disease 2019 (COVID-19), potential threats that would affect antibiotic stewardship should not be neglected. Since the facile accessibility and little knowledge of antibiotics in China community, the irrational use of antibiotics increased for prophylaxis and self-treatment [30]. As a consequence of COVID-19, the disruption of vaccination and other health service will also increase risk of infection that ultimately leads to more prevalence non-prescription antibiotics use. Considering the COVID-19 pandemics may last for years, the high prevalence of non-prescription antibiotics use would undoubtfully challenge the stewardship system and pose threat to the antibiotic resistance [31, 32].

To conclude, PPS sampling method has strengthened the power of our study that can clarify the age-specific frequency and reasonably representative of the population in the community. Thus, providing data for China to better understand the quantity, types, and patterns of nonprescribed antibiotics used at the population, which can inform policies, regulations, and interventions to ensure that antibiotics are used appropriately. We believe that our study would be of great importance in assisting national-wide health care policy making.

This study has some limitations. First, the 9-item antibiotic use knowledge questionnaire has not been validated in previous studies. However, these 9 questions raised fundamental factors including antibiotic indications, prescription and administration principles, adverse effects and prophylactic use. Second, we have only onesite survey in Zhejiang province, more data of other provinces will be more representative. Third, PPS sampling causes regional and family clustering. However, we divided sample into 50 clusters and only investigate one person in each household. In addition, the distribution 
of age and gender in participants were similar to those in source population. All of these could reduce bias.

\section{Conclusions}

In conclusion, non-prescription antibiotics use for cough is prevalent in the community. This result may reflect the real-world situation in China national-wide. Effective policies and regulations should be made to inverse this situation and efforts should be exerted to slow down the pace of AMR.

\begin{abstract}
Abbreviations
AMR: Antimicrobial resistance; URTI: Upper respiratory tract infection; CDC: Center for disease control and prevention; PPS: Probability-proportionate-tosize; PAD: Portable android device; SD: Standard deviation; IQR: Inter-quartile range; OR: Odds ratio; Cl: Confidence interval; SE: Standard error; COVID-19: Corona virus disease 2019
\end{abstract}

\section{Supplementary Information}

The online version contains supplementary material available at https://doi. org/10.1186/s13756-021-00998-5.

Additional file 1. Figure 1. Process of randomization and ProbabilityProportionate-to-Size (PPS) sampling. Table 1. Clusters in each township. Table 2. The antibiotic related knowledge of participants $(\mathrm{N}=3034)$.

\section{Acknowledgements}

We gratefully acknowledge investigation team in Yiwu CDC and staffs in Yiwu townships for their super work. This study is part of China Pertussis Project (CPP).

\section{Authors' contributions}

$H H, Z S$, JY and ZC planned and designed the study; YL, XT, LD, YZ and YC collected the data; $\mathrm{HH}$ and $\mathrm{ZC}$ coordinated the research; $\mathrm{YL}$ performed the statistical analysis and wrote the manuscript; $\mathrm{HH}$ revised the manuscript. The corresponding authors are the guarantors for the data and have full access to all data. All authors read and approved the final manuscript.

\section{Funding}

This work was supported by the Medical Health Science and Technology Project of Zhejiang Province, China under Grants [Number 2019KY052, 2019KY059 and 2021 KY118], National Natural Science Foundation of China (NSFC) [Grant Number 81973106] and Beijing Municipal Natural Science Foundation [Grant Number 19L2060].

\section{Availability of data and materials}

The data can be available from the corresponding author upon reasonable request.

\section{Declarations}

\section{Ethics approval and consent to participate}

The study protocol was approved by the ethics committee of the Chinese Centre for Disease Control and Prevention (ICDC-2019010) before study initiation. Written informed consent was obtained from all study participants or their guardian/parents prior to inclusion in the study. In order to protect participants' confidentiality, the data was guarded by a person and exported without participants' name or informed consent form.

\section{Consent for publication}

Not applicable.

\section{Competing interests}

All authors declare that they have no conflicts of interest.

\section{Author details}

${ }^{1}$ Institute for Immunization and Prevention, Zhejiang Provincial Center for Disease Control and Prevention, No. 3399 Binsheng Road, Binjiang district, Hangzhou City 310051, Zhejiang Province, China. ${ }^{2}$ Chinese People's Liberation Army General Hospital, Beijing, China. ${ }^{3}$ State Key Laboratory of Infectious Disease Prevention and Control, National Institute for Communicable Disease Control and Prevention, Chinese Center for Disease Control and Prevention, Beijing, China. ${ }^{4}$ School of Public Health, Xiamen University, Xiamen, China.

Received: 21 May 2021 Accepted: 21 August 2021

Published online: 30 August 2021

\section{References}

1. Li Y. China's misuse of antibiotics should be curbed. BMJ. 2014;348:g1083.

2. Yuefeng $L$, Keqin R, Xiaowei R. Use of and factors associated with selftreatment in China. BMC Public Health. 2012;12:995.

3. https://www.who.int/news-room/fact-sheets/detail/antimicrobial-resis tance.

4. Ayukekbong JA, Ntemgwa M, Atabe AN. The threat of antimicrobial resistance in developing countries: causes and control strategies. Antimicrob Resist Infect Control. 2017;6:47.

5. Sakeena MHF, Bennett AA, McLachlan AJ. Non-prescription sales of antimicrobial agents at community pharmacies in developing countries: a systematic review. Int J Antimicrob Agents. 2018;52(6):771-82.

6. Heddini A, Cars O, Qiang S, Tomson G. Antibiotic resistance in China-a major future challenge. Lancet. 2009;373(9657):30.

7. Li X, Lu J, Hu S, Cheng KK, De Maeseneer J, Meng Q, Mossialos E, Xu DR, Yip W, Zhang H, et al. The primary health-care system in China. Lancet. 2017;390(10112):2584-94

8. Yip WC, Hsiao WC, Chen W, Hu S, Ma J, Maynard A. Early appraisal of China's huge and complex health-care reforms. Lancet. 2012:379(9818):833-42.

9. Zhou XD, Li L, Hesketh T. Health system reform in rural China: voices of healthworkers and service-users. Soc Sci Med. 2014;117:134-41.

10. Li JC, Zhang M, Li YC, Duan XL, Wang LM. Prevalence and influencing factors of respiratory symptoms among people aged 40 years and above in China. Zhonghua Liu Xing Bing Xue Za Zhi. 2018;39(6):786-91.

11. Lai K, Chen R, Lin J, Huang K, Shen H, Kong L, Zhou X, Luo Z, Yang L, Wen $F$, et al. A prospective, multicenter survey on causes of chronic cough in China. Chest. 2013;143(3):613-20.

12. Fang Y. China should curb non-prescription use of antibiotics in the community. BMJ. 2014;348:g4233.

13. Morgan DJ, Okeke IN, Laxminarayan R, Perencevich EN, Weisenberg S. Non-prescription antimicrobial use worldwide: a systematic review. Lancet Infect Dis. 2011;11(9):692-701.

14. Wang $X$, Peng D, Wang W, Xu Y, Zhou X, Hesketh T. Massive misuse of antibiotics by university students in all regions of China: implications for national policy. Int J Antimicrob Agents. 2017;50(3):441-6.

15. Chang J, Xu S, Zhu S, Li Z, Yu J, Zhang Y, Zu J, Fang Y, Ross-Degnan D. Assessment of non-prescription antibiotic dispensing at community pharmacies in China with simulated clients: a mixed cross-sectional and longitudinal study. Lancet Infect Dis. 2019;19(12):1345-54.

16. Kuang L, Liu Y, Wei W, Song X, Li X, Liu Q, Hong W, Liu Q, Li J, Chen Z, et al. Non-prescription sale of antibiotics and service quality in community pharmacies in Guangzhou, China: a simulated client method. PLoS ONE. 2020;15(12):e0243555.

17. Lin L, Fearon E, Harbarth S, Wang X, Lu C, Zhou X, Hargreaves JR. Decisions to use antibiotics for upper respiratory tract infections across China: a large-scale cross-sectional survey among university students. BMJ Open. 2020;10(8):e039332.

18. Xu Y, Lu J, Sun C, Wang X, Hu YJ, Zhou X. A cross-sectional study of antibiotic misuse among Chinese children in developed and less developed provinces. J Infect Dev Ctries. 2020;14(2):129-37.

19. Bronchial Asthmatic Group of Respiratory Medicine Branch of Chinese Association. Bronchial asthmatic diagnosis and treatment quidelines. 
Chin J Tuberc Respir Dis. 2016;39(5):323-54. https://doi.org/10.3760/ cma.jissn.1001-0939.2016.05.003.

20. Turner AG. Sampling strategies. Handbook on designing of household sample surveys. Geneva: United Nations Statistics Division; 2003.

21. Gong W, Taighoon Shah M, Firdous S, Jarrett BA, Moulton LH, Moss WJ, Hayford K, O'Brien KL, Chandir S. Comparison of three rapid household survey sampling methods for vaccination coverage assessment in a periurban setting in Pakistan. Int J Epidemiol. 2019;48(2):583-95.

22. Binkin N, Sullivan K, Staehling N, Nieburg P. Rapid nutrition surveys: how many clusters are enough? Disasters. 1992;16(2):97-103.

23. Morice AH, Jakes AD, Faruqi S, Birring SS, McGarvey L, Canning B, Smith JA, Parker SM, Chung KF, Lai K, et al. A worldwide survey of chronic cough: a manifestation of enhanced somatosensory response. Eur Respir J. 2014;44(5):1149-55.

24. Nowakowska M, van Staa T, Molter A, Ashcroft DM, Tsang JY, White A, Welfare W, Palin V. Antibiotic choice in UK general practice: rates and drivers of potentially inappropriate antibiotic prescribing. J Antimicrob Chemother. 2019;74(11):3371-8

25. Alhomoud F, Aljamea Z, Almahasnah R, Alkhalifah K, Basalelah L, Alhomoud FK. Self-medication and self-prescription with antibiotics in the Middle East-do they really happen? A systematic review of the prevalence, possible reasons, and outcomes. Int J Infect Dis. 2017;57:3-12

26. Ocan M, Obuku EA, Bwanga F, Akena D, Richard S, Ogwal-Okeng J, Obua C. Household antimicrobial self-medication: a systematic review and meta-analysis of the burden, risk factors and outcomes in developing countries. BMC Public Health. 2015;15:742.

27. The AWaRe classification of antibiotics database. Geneva: World Health Organization; 2019. https://adoptaware.org/. Cited 25 Jan 2021.

28. Kalungia A, Godman B. Implications of non-prescription antibiotic sales in China. Lancet Infect Dis. 2019;19(12):1272-3.

29. Dar OA, Hasan R, Schlundt J, Harbarth S, Caleo G, Dar FK, Littmann J Rweyemamu M, Buckley EJ, Shahid M, et al. Exploring the evidence base for national and regional policy interventions to combat resistance. Lancet. 2016;387(10015):285-95.

30. Getahun H, Smith I, Trivedi K, Paulin S, Balkhy HH. Tackling antimicrobial resistance in the COVID-19 pandemic. Bull World Health Organ. 2020;98(7):442-442A.

31. Huttner BD, Catho G, Pano-Pardo JR, Pulcini C, Schouten J. COVID-19: don't neglect antimicrobial stewardship principles! Clin Microbiol Infect. 2020;26(7):808-10

32. Usman M, Farooq M, Hanna K. Environmental side effects of the injudicious use of antimicrobials in the era of COVID-19. Sci Total Environ. 2020;745:141053

\section{Publisher's Note}

Springer Nature remains neutral with regard to jurisdictional claims in published maps and institutional affiliations.
Ready to submit your research? Choose BMC and benefit from:

- fast, convenient online submission

- thorough peer review by experienced researchers in your field

- rapid publication on acceptance

- support for research data, including large and complex data types

- gold Open Access which fosters wider collaboration and increased citations

- maximum visibility for your research: over 100M website views per year

At BMC, research is always in progress.

Learn more biomedcentral.com/submissions 